\title{
Enterprise Credit Risk Evaluation Modeling and Empirical Analysis via GRNN Neural Network
}

\author{
Chenyue Zhu ${ }^{1}$, Zhiwei Cheng ${ }^{1}$, Yuanbiao Zhang ${ }^{2} \&$ Xiaoting $\mathrm{Hu}^{1}$ \\ ${ }^{1}$ School of International Business, Jinan University, Guangdong, China \\ ${ }^{2}$ School of Electrical Information, Jinan University, Guangdong, China \\ Correspondence: Chenyue Zhu, School of International Business, Jinan University, Guangdong, ON., M3A 2K7, \\ Canada. Tel: 1-613-947-3592. E-mail: joannazhu0213@foxmail.com
}

Received: July 17, 2015

Accepted: August 12, 2015

Online Published: September 25, 2015

doi:10.5539/ijef.v7n10p173

URL: http://dx.doi.org/10.5539/ijef.v7n10p173

\begin{abstract}
Enterprise credit risk evaluation is of great importance in the credit process in the commercial banking system. Based on the previous researches on the commercial bank credit risk assessment model, this essay starts from analyzing the factors which will influence the commercial bank credit management, and then moves on to build a more comprehensive credit risk evaluation index system which contains 3 levels of 12 indexes. Afterwards, this essay chooses the GRNN Neural Network to be the commercial bank credit risk assessment model by means of MATLAB. All the chosen samples have been put into empirical analysis and the results shows that the discriminate accuracy rate for the good enterprises is $92.16 \%$ while for the bad enterprises is $93.75 \%$ in this model. Therefore, this outstanding discriminate accuracy rate proves that this model could be used effectively and efficiently.
\end{abstract}

Keywords: credit risk evaluation model, GRNN Neural Network, machine learning, commercial bank

\section{Introduction}

The credit risk assessment of commercial bank is vital to credit loan. As the rate of bad account of commercial bank is high, the credit risk assessment is related to the profit of commercial bank and the stability of financial system which will affects he people's livelihood. For more efficient credit risk assessment, it is crucial to develop a valid credit risk assessment model.

Traditional statistical methods have to obey normal distribution. Nevertheless, The US subprime mortgage crisis has proved that the data of credit risk assessment of banks does not obey normal distribution. The limitations of traditional statistical methods motivates scholars to seek for new solutions. With the development of computer science and technology, machine learning has been more popular since 20th century, scholars attempt to apply the theory of machine learning to redevelop credit risk assessment model.

More foreign literature on this area emerged in recent years which provides more new methods. Basle Agreement II and the financial crisis in America motivate banks to update their credit risk assessment model.

Perez (2006) summarized 30 literature which applies neutral network to the classification of companies, Perez also discussed the parameter settings and selection of input and output, and the results were analyzed. Chih-Fong Tsai (2008) classified company samples, applied neutral network to predict and compare the possibility of bankruptcy of companies. Efstathios Kirkos (2015) provided the literature review of bankruptcy prediction till 2012. Judging from the review, we find neutral network method is used. Besides, new algorithms of machine learning have an established place in the area of bankruptcy prediction.

Foreign scholars assessed the credit risk of commercial banks by utilizing similar methods. Ravi Kumar and Ravi (2007) provided the assessment of bank risk from 1968 to 2005 and details of parameters and data. Milad Malekipirbazari (2015) applied the random forests algorithm in machine learning to measure the credit status of borrowers from network P2P loans.

The progress of domestic research is much slower than abroad. The data are scarce, and compared with foreign countries, there still is a gap in the development level of mathematical finance. In a nutshell, domestic evaluation methods of commercial bank credit risk can be divided into machine learning and other directions. 
Some scholars use machine learning method. Liu Yundao, Wu Chong (2005) utilized SVM model to build the enterprise credit risk evaluation model, and they use data came from a bank in Harbin whose correct rate of test sample sets achieved $80 \%$, their results indicates the feasibility of the theory of machine learning. Cheng Jian, Zhu Xiaoming (2007) put forward a verification model of enterprise credit risk evaluation which contains the value of AUC and proportion of conditional entropy, they compared linear discriminant model, logit model, Probit model and neural network model, the comparison results showed that neural network model have the best sample testability, and adaptability of the external sample is not very strong. Whereas, the setting details and techniques of data handling are not provided in the paper. Wu Chong, Xia Han (2009) suggested a credit risk evaluation model based on hierarchical support vector machines with 5 types of classification, the results of the model is excellent with 87 percent of total successful rate. Nevertheless, the recognition accuracy between good companies and bad companies was not given.

Some scholars use other method to measure the enterprise credit risk. Zhou Lili, Ding Dongyang (2011) utilized Bayesian hierarchical model and Markov model to handle data from a commercial bank, and the probability of default for all lenders was calculated. Yet the actual prediction interval is too large which can't make this argument convincing. Zhao Yijun (2013) came up with enterprise credit risk evaluation model based on cash flow, they used the data of cash flow with 60 percent of accuracy rate. However the accuracy rate is too low to be convincing.

In this paper, we take the application of GRNN neutral network in credit risk assessment of commercial banks as research study. We utilize qualitative analysis and quantitative calculation by combining relevant theories and empirical practice. Firstly, we look into the factors which affect the process of commercial bank credit risk assessment, and a more comprehensive commercial bank credit risk evaluation indicator system is established. Then we structure commercial bank credit risk assessment model by applying GRNN neutral network. Finally, we verify effectiveness and feasibility of the model by empirically analyzing the data of all listed companies in China.

\section{The Establishment of Commercial Bank Credit Risk Evaluation Indicator System}

As the indicators of commercial bank credit risk evaluation involve a wide range, If we filter indicators by referring to empirical and subjective judgment, some important indicators can be neglected, or minor indicators that have relatively smaller influence on credit risk evaluation will be selected, and it might make indicator system highly correlated which will cause inaccurate results in risk assessment and loan decision will be affected. To establish a more scientific and rational evaluation indicator system, we follow two steps: Firstly we extract contributory factors according to expert advice; then we apply of statistical methods to filter preliminary indicators, remove indicators which are highly related and have little contribution to the credit risk assessment, and add missing key indicators to perfect evaluation indicators system.

It is both conventional and expedient to divide the Method section into labeled subsections. These usually include a section with descriptions of the participants or subjects and a section describing the procedures used in the study. The latter section often includes description of (a) any experimental manipulations or interventions used and how they were delivered-for example, any mechanical apparatus used to deliver them; (b) sampling procedures and sample size and precision; (c) measurement approaches (including the psychometric properties of the instruments used); and (d) the research design. If the design of the study is complex or the stimuli require detailed description, additional subsections or subheadings to divide the subsections may be warranted to help readers find specific information.

Include in these subsections the information essential to comprehend and replicate the study. Insufficient detail leaves the reader with questions; too much detail burdens the reader with irrelevant information. Consider using appendices and/or a supplemental website for more detailed information.

To make a more comprehensive evaluation, we try to take all contributory factors into consideration to avoid missing key indicators. In order to establish hierarchical relationship between indicators, we classify indicators by the application of Goal-Oriented analysis.

According to previous experience and recommendations of experts, we divide all indicators into five parts, they are profitability, development capacity, operational capacity, repayment capability and corporate power. Then we subdivide these five second-class indicators, the results are depicted in the table below. 
Table 1. The establishment of evaluation indicators system

\begin{tabular}{lcc}
\hline First-class indicators & Second-class indicators & Third-class indicators \\
\hline & profitability & Return on Total Assets \\
& & Net Profit Margin on Sales \\
& Return on Equity \\
& development capacity & Main Income Grow Rate \\
Commercial bank credit & & Growth rate of total assets \\
risk evaluation system & EPS growth rate \\
& & rate of stock turnover \\
& & Total asset turnover \\
& repayment capability & asset velocity \\
& & Debt Asset ratio \\
& corporate power & Brand dependence \\
& & Independent coefficients \\
\hline
\end{tabular}

Evaluation indicator system only contains quantitative indicators whose data can be directly obtained from the listed companies' financial and statistical information, and the data is accurate and reliable. As the data of qualitative indicators need to be captured through questionnaire investigation, expert evaluation or other methods which will cause big deviations, and it is not consistent with the thrust of machine learning, qualitative indicators like brand identity are not discussed in this paper.

\section{Explanations on the indicators of the Credit Risk Evaluation Index System}

\subsection{Profitability}

1) Return on Total Assets

$$
R O A=\frac{\text { Net Income }}{\text { AverageTotal Asset }}
$$

The return on assets (ROA) shows the percentage of how profitable a company's assets are in generating revenue, it is a key indicator to evaluate operational effectiveness of enterprise assets. The higher the ratio, the higher management level and asset utilization efficiency of enterprises, corporate profitability is stronger.

2) Net Profit Margin on Sales

$$
\text { Net Profit Margin on Sales }=\frac{\text { Net } \text { Return }}{\text { Net } \text { Sales }}
$$

It is a key indicator to measure the level of enterprise management. Net Profit Margin on Sales reflects the enterprise's ability to earn profits by selling its products. The higher the ratio, the stronger the ability to generate revenue by expanding sales.

3) Return on Equity

$$
\text { Return on Equity }=\frac{\text { Net Return }}{\text { Return on Average Equity }}
$$

This is a measure of return on average equity which give a more accurate depiction of a company's corporate profitability, especially in instances where the value of the shareholders' equity has changed considerably during a fiscal year. The higher the value is, the stronger a corporation's capacity of using its own capital gain is, the operation efficiency of enterprise investors is better, and the higher the extent of creditor's rights guarantee.

\subsection{Development Capacity}

1) Main Income Grow Rate

$$
\text { Main Income Grow Rate }=\frac{\text { The Current Main Business Revenue }}{\text { The Main Business Revenue in Last Period }} \times 100 \%
$$

This is a key indicator to measure present development situation and market capacity of enterprises, it is also the forecast of development trend of enterprise business. If Main Income Grow Rate is greater than zero, it means the main business income of the company in the current year. And a high growth rate indicates a high growth speed which means a promising future of the company. On the contrary, if the rate is less than zero, then the 
products of the company have a problem of inferior quality-high price, and market share has been shrinking.

2) Growth Rate of Total Assets

$$
\text { Growth Rate of Total Assets }=\frac{\text { Total Assets Growth in } \text { this year }}{\text { Total Assets Brought Forward }} \times 100 \%
$$

This indicator measures enterprises' ability of expanding total assets which demonstrates the impact of enterprise-scale on enterprise development level. The higher the value of the indicator, the faster of expansion of assets in a certain period is.

3) EPS Growth Rate

$$
\text { EPS Growth Rate }=\frac{\text { Earnings per Share in the Current Period }- \text { Earnings per Share in Prior Period }}{\text { Earnings per Share in Prior Period }}
$$

The indicator reflects the growth of earnings per share, and the higher the value of the indicator is, the better the situation is. The indicator represents a dynamic trend of development, it is different from EPS which distinguishes if the corporation is successfully operated.

\subsection{Operational Capacity}

1) Inventory Turnover Ratio

The Inventory turnover rate is a measure of the number of times inventory is sold or used in a time period such as a year. It measures the efficiency of enterprise production and operation process of inventory operation, and the higher the rate is, the higher cash ability is. A low turnover rate may point to overstocking, obsolescence, or deficiencies in the product line or marketing effort. However, in some instances a low rate may be appropriate, such as where higher inventory levels occur in anticipation of rapidly rising prices or expected market shortages.

$$
\text { Inventory Turnover Ratio }=\frac{\text { Cost of Goods Sold }}{\text { Average Inventory }}
$$

2) Total Asset Turnover

$$
\text { Total Asset Turnover }=\frac{\text { Net Sales Revenue }}{\text { Average Total Assets }}
$$

Asset turnover is a financial ratio that measures the efficiency of a company's use of its assets in generating sales revenue or sales income to the company. Companies with low profit margins tend to have high asset turnover, while those with high profit margins have low asset turnover (Note 1).

\subsection{Repayment Capability}

1) Assets Flowing Rate

$$
\text { Assets Flowing Rate }=\frac{\text { Liquid Assets }}{\text { Total Assets }}
$$

This indicator reflects the repayment capacity of a corporation in the near future. A high rate means a fast speed of cost recovery, and a relatively small rate indicates a higher rate of repayment and lower creditworthiness.

2) Debt Ratio

$$
\text { Debt Ratio }=\frac{\text { Total Debt }}{\text { Total Assets }}
$$

Debt Ratio is a financial ratio that indicates the percentage of a company's assets that are provided via debt. If the ratio is less than 0.5 , most of the company's assets are financed through equity. If the ratio is greater than 0.5 , most of the company's assets are financed through debt. Companies with high debt ratios are said to be highly leveraged. The higher the ratio, the greater risk will be associated with the firm's operation (Note 2).

\subsection{Corporate Power}

1) Brand Dependence

Brand Dependence. Profits that Belong to the Owner of the Parent Company Total Profit

$$
\text { Brand Dependence }=\frac{\text { Brand Dependence }}{\text { Total Profit }}
$$


Brand Dependence measures the contribution of parent company to total profit. A high Brand Dependence value indicates strong independence of parent company and weak independence of branch company, and the company is not widely expanded or it still in its early stages of development. If the value if the indicator is small, then branch company is highly independent, and bears sole role in the company's overall operations.

1) Independent Coefficients

$$
\text { Independent Coefficients }=\frac{\text { Intangible Assets }}{\text { Total Fixed Assets }}
$$

Independent Coefficients reflects the importance of corporate brand image. Corporate brand image is the distinctive traits in market and public mind, it reflects consumers' cognition and evaluation to the product, which plays a vital role in enterprise's development. A high value of the indicator means high visibility and reputation of the enterprise. Only with a high market occupancy in the competition that the source of enterprise' profits is guaranteed.

\section{Establishment of the Credit Risk Assessment Model (Note 3)}

Based on all the indicators identified above, it is high time to establish the credit risk assessment model. Given the fact that the loan system in commercial banking is a very complicated nonlinear system, the traditional theory of general linear can hardly reflect the principles behind, which results in achieving effects well below the previous expectations. Therefore, this essay try to use the machine learning, which suits the nonlinear modeling for credit risk modeling. Although the BP neural network has been widely used before, it still needs past experience to help determine the number of nodes and layers. So here in this essay GRNN Neutral Network is used for its relatively fixed structure, also it can reduce the problem of poor fitting or overfitting to some extent.

\subsection{The Theoretical Basis for the GRNN Neural Network}

The theoretical basis for the GRNN Neural Network is nonlinear regression analysis, thus, the regression process between the dependent variable $\mathrm{X}$ and the independent variable $\mathrm{Y}$ can be replaced by calculating the greatest probability of $\mathrm{y}$. So just assume the joint density function of random variables $\mathrm{x}$ and $\mathrm{y}$ is $f(x, y)$, and $\mathrm{x}$ corresponds to the observed value of $\mathrm{X}$, therefore, the conditional mean of the $\mathrm{y}$ to $\mathrm{x}$ regression is:

Therefore, the nonparametric estimator of $f(x, y)$ is:

$$
Y=E(y / X)=\frac{\int_{-\infty}^{\infty} y f(X, y) d y}{\int_{-\infty}^{\infty} f(X, y) d y}
$$

$$
f(X, y)=\frac{1}{n(2 \pi)^{\frac{p+1}{2}} \sigma^{p+1}} \sum_{i=1}^{n} \exp \left[-\frac{\left(X-X_{i}\right)^{T}\left(X-X_{i}\right)}{2 \sigma^{2}}\right] \exp \left[-\frac{\left(X-Y_{i}\right)^{2}}{2 \sigma^{2}}\right]
$$

Among them, $\mathrm{Xi}$, Yi are the sample observations of the random variables $\mathrm{x}, \mathrm{y} ; \mathrm{n}$ is the sample size; $\mathrm{p}$ is the dimensions of the random variables $\mathrm{x} ; \sigma$ is the width factor of the Gaussian function, here is also called the smoothing factor.

Then put (14) into (13), and get

$$
Y(X)=\frac{\sum_{i=1}^{n} \exp \left[-\frac{\left(X-X_{i}\right)^{T}\left(X-X_{i}\right)}{2 \sigma^{2}}\right] \int_{-\infty}^{+\infty} y \exp \left[-\frac{\left(Y-Y_{i}\right)^{2}}{2 \sigma^{2}}\right] d y}{\sum_{i=1}^{n} \exp \left[-\frac{\left(X-X_{i}\right)^{T}\left(X-X_{i}\right)}{2 \sigma^{2}}\right] \int_{-\infty}^{+\infty} \exp \left[-\frac{\left(Y-Y_{i}\right)^{2}}{2 \sigma^{2}}\right] d y}
$$

For further simplification, the function can be written like that.

$$
Y(X)=\frac{\sum_{i=1}^{n} \exp \left[-\frac{\left(X-X_{i}\right)^{T}\left(X-X_{i}\right)}{2 \sigma^{2}}\right]}{\sum_{i=1}^{n} \exp \left[-\frac{\left(X-X_{i}\right)^{T}\left(X-X_{i}\right)}{2 \sigma^{2}}\right]}
$$


In function (16), the estimate value of $\mathrm{Y}(\mathrm{X})$ is the weighted averages of all sample observations $\mathrm{Yi}$, and all the weighted factors for the values of the observation samples is the Euclidean distance between the sample $\mathrm{Xi}$ and $\mathrm{X}$.

Therefore, when the smoothing factor is getting really big, the value of $\mathrm{Y}(\mathrm{X})$ can be quite equal to the averages of all the sample dependent variables. But on the opposite, when the smoothing factor is getting close to 0 , the value of $\mathrm{Y}(\mathrm{X})$ can be almost equal to the values of the training samples, which lead to the bad results, also can be interpreted that the generalization ability of this network is terrible. However, when the value of the smoothing factor is intermediate and not go to extremes, the reasonable value of $\mathrm{Y}(\mathrm{X})$ can be achieved because all the dependent variables have been considered and all the dependent variables close to the forecasting values are given bigger weights.

\subsection{Stablishment of GRNN Neural Network}

GRNN Neutral Network is similar to RBF network in structure. It consists of 4 layers, as is shown in Figure 1, which are input layer, pattern layer, summation layer and output layer. Once you input data in the form of $X=\left[x_{1}, x_{2}, \ldots, x_{n}\right]^{T}$, a corresponding $Y=\left[y_{1}, y_{2}, \ldots, y_{k}\right]^{T}$ will be the output.

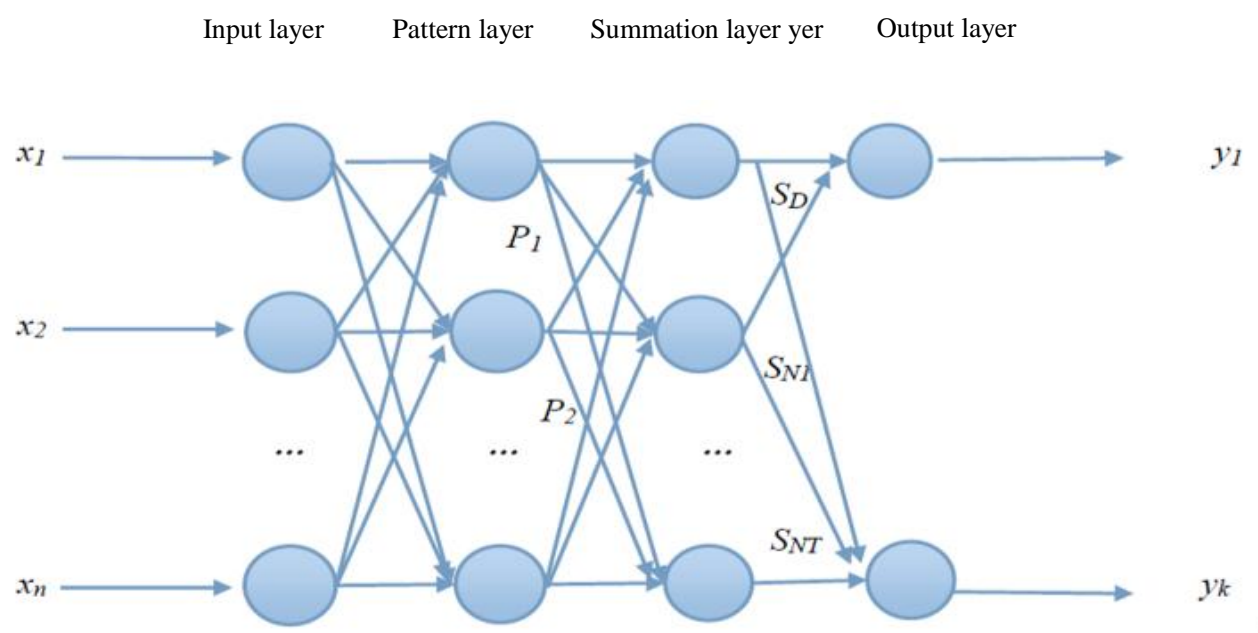

Figure 1. Generalized regression networks structure

\section{1) Input layer}

The number of the neuron cells in the input layer is equal to the number of dimensions of the input vector in the learning sample, and each neuron cell is a simple distribution unit, which can pass the input variables to the pattern layer directly.

2) Pattern layer

The number of the neuron cells in the pattern layer equals to the number of the samples which is represented with $\mathrm{n}$. Therefore, the function of the transferring process when all neuron cells face different samples is listed below.

$$
p_{i}=\exp \left[-\frac{\left(X-X_{i}\right)^{T}\left(X-X_{i}\right)}{2 \sigma^{2}}\right], i=1,2, \ldots n
$$

\section{3) Summation layer}

In the summation layer, two different kinds of neuron cells are used for summation.

The formula for one kind of the neuron cells is:

$$
\exp \left[-\frac{\left(X-X_{i}\right)^{T}\left(X-X_{i}\right)}{2 \sigma^{2}}\right]
$$


which means an arithmetic sum of all neuron cells in the pattern layer, and the weight between the pattern layer and all neuron cells is 1 . Thus, the transfer function is listed below.

$$
S_{D} \sum_{i=1}^{n} P_{i}
$$

The formula for the other kind of the neuron cells is:

$$
\sum_{i=1}^{n} Y_{i} \exp \left[-\frac{\left(X-X_{i}\right)^{T}\left(X-X_{i}\right)}{2 \sigma^{2}}\right]
$$

This formula represents a weighted sum of all neuron cells in the pattern layer. The weight between the I-th neuron in the pattern layer and the $\mathrm{j}$-th neuron in the summation layer is the right value of the $\mathrm{j}$-th element in the output sample Yi. And the transfer function is listed below.

$$
S_{N j}=\sum_{i=1}^{n} y_{i j} P_{i}, j=1,2, \ldots k
$$

4) Output layer

The number of the neuron in the output layer is equal to the number of dimensions of the output vector in the learning sample, which is represented with a $k$. The output in the summation layer is divided by all neural cells and the output of the $j$-th neural cell is the right value of the $j$-th element in the output sample $Y(X)$. It can be formulated like that.

$$
y_{j}=\frac{S_{N j}}{S_{D}}, j=1,2, \ldots, k
$$

\subsection{Parameter Modification in the GRNN Neural Network}

Because the GRNN neural network learning rate is an undetermined coefficients, so an iterative algorithm can be used to find the optimal learning rate. To be specific, this method is to minimize the sum of squared errors, so this essay modify the parameter from 0.1 to 2 with the step of 0.1 . Not until the sum of squared errors reaches the lowest can this model found the optimal learning rate.

\section{Empirical Analysis}

\subsection{Data Selection and Manipulation}

Difficulty to obtaining the commercial banks' loans to customers and the default data is the primary problem in credit risk assessment studies. No matter at home or abroad, the bad debts, as well as the default data in commercial banks are trade secrets which researchers can hardly obtain. Therefore, the selection of internal data sample is the primary challenge in the research process. To solve this problem, the common practice is to use the data of listed companies as research samples.

Therefore, this essay selects all the 2584 listed enterprises by the end of 2014 in China, excluding the B-share companies, the financial corporations (for they do not have important indexes such as current ratio and quick ratio, etc.) and the enterprises which have a problem with their financial data. Thus, the rest of the enterprises are used as samples.

First of all, this essay try to deal with the missing values. The method used here is to make the missing values equal to the averages in the same industry.

In addition, this essay conduct a preliminary classification of all the enterprises. The first step to do it is to find out all the ST-marked companies by the end of 2014. Being marked by ST means that kind of companies have undergone consecutive losses or their net asset per share is below bar or the enterprises were legal insolvency. To be specific, these enterprises have already have their financial distress, their level of credit conditions is going down and there is a great likelihood of default. So these enterprises are labeled as "default samples", also classified as the "poor credit" category. In the meantime, the other enterprises can be treated as normal sample and classified as the "good credit". 
However, there will be 2000 good enterprises and only 43 bad enterprises in this measurement. But for a neutral network, the huge difference between the categories of the samples will lead to overfitting, which will have a bad effect on the accuracy. Therefore, it is appropriate to choose some representatives by proportion for training. Thus, 101 good enterprises and 31 bad enterprises have been chosen and they are used for difference purposes: $50 \%$ for training and 50\% for checking. Since no standard for enterprise judgement exists, this essay use the measurement of earnings per share. Earnings per share are often used to reflect the company's operating results, measure the profit level of common stock and investment risk, also, it is a good indication for investors and other users to evaluate the enterprise' profitability, forecast business growth potential and make economic decisions. Apparently, the more earnings per share, the more rate of return for the stakeholders. So, it is reasonable to choose earnings per share as a measurement for a good or bad company in the sense of economy and in the sense of modeling for it is not relevant to any of the indexes in the credit risk evaluation index system, which assures the model to be fair and feasible.

\subsection{Model Results}

50 good enterprises and 15 bad enterprises are selected as a sample which are sent to the credit risk evaluation model which has already been built for training while another 51 good enterprises and 16 bad enterprises are used to do the out-of-sample test. Set 0.5 as the distinguishing point, therefore, when the output is greater than 0.5 , it can be identified as a good enterprise, otherwise, it is a bad one. The results are listed below.

Table 2. Test sample simulation results

\begin{tabular}{ccccc}
\hline \multirow{2}{*}{ classification } & \multicolumn{2}{c}{ distinguishing point } & \multirow{2}{*}{ Sum } \\
\cline { 3 - 4 } & & Good enterprise & Bad enterprise & \\
\hline \multirow{2}{*}{ number } & Good enterprise & 47 & 4 & 51 \\
& Bad enterprise & 1 & 15 & 16 \\
\multirow{2}{*}{ percentage } & Good enterprise & $92.16 \%$ & $7.84 \%$ & $100 \%$ \\
& Bad enterprise & $6.25 \%$ & $93.75 \%$ & $100 \%$ \\
\hline
\end{tabular}

This easy uses the sample data to train the GRNN Neural Network and uses another sample of enterprises to do the out-of-sample test. The results shows that the discriminate accuracy rate for the good enterprises is $92.16 \%$ while for the bad enterprises is $93.75 \%$ in this model, and the discriminate accuracy rate for all the enterprises is $92.537 \%$. Compare to the probability to pick a good enterprises among a total of 130 enterprises (100 good enterprises and 30 bad enterprises) which is 100/130 (almost equal to 76.9\%), the results in this model is much more accurate. Therefore, this credit risk assessment model is of great precision, which means it is highly applicable and effective.

\section{Conclusion}

On the basis of the previous dissertations on the commercial bank credit risk assessment models, this essay analyses the factors which will influence the commercial bank credit management first, and then builds a more comprehensive credit risk evaluation index system. Afterwards, this essay chooses the GRNN Neural Network to be the commercial bank credit risk assessment model. All the chosen samples have been put into empirical analysis and the results shows that the discriminate accuracy rate is quite precise

The conclusions are as follows:

1) The detailed pre-processing of data can improve the forecast accuracy. It is perfectly shown in this essay that the detailed steps of data pre-processing and the reasonable selection of sample size are vital to the precise results.

2) GRNN Neural Network can be quite applicable in the commercial bank credit risk assessment. The discriminate accuracy rate in this essay is higher than the standard BP Neural Network and the Logistic Regression model, which proves that using the GRNN Neural Network to assess the credit risk is useful and effective.

3) Feasible commercial bank credit risk evaluation index system has a great influence on the enterprise credit risk assessment. This essays begins with the relevant theoretical analysis, and then dig in the factors which influence the credit risk assessment in order to build a commercial bank credit risk evaluation index system which contains five aspects of 12 specific measurements with references.

That is to say, the credit risk assessment model built in this easy suits the Chinese banking system. On one hand, 
this model can play a supporting role in deciding whether to give a loan to an enterprise or not, on the other hand, it can prevent and reduce the credit risk in financial markets and improve the level of management of the commercial banks, thus it has good prospects. However, given the paucity of public data in China, this essay only classify the enterprises into the default ones and the non-default ones. A shortage of this essay though, it points out the direction for the following researches that to classify and grade the enterprises more specific, which will result in a more accurate model of credit risk assessment in commercial banks.

\section{References}

Cheng J., \& Xiaoming, Z. (2007). Research on Performance Validation of Credit Risk Models. Journal of Shanxi University of Finance and Economics, 29(2), 86-92. http://dx.doi.org/1007-9556(2007)02-0086-07

Chong W., \& Han X. (2009). Credit Risk Assessment in Commercial Banks on Five-class Support Vector Machines. Ensemble Journal, 28(4), 57-61. http://dx.doi.org/1003-5192(2009)04-0057-05

Kirkos, E. (2015). Assessing Methodologies for Intelligent Bankruptcy Prediction. Artificial Intelligence Review, 43(1), 83-123. http://dx.doi.org/10.1007/s10462-012-9367-6

Kumar, P. R., \& Ravi, V. (2007). Bankruptcy prediction in banks and firms via statistical and intelligent techniques-A review. European Journal of Operational Research, 180(1), 1-28. http://dx.doi.org/10.1016/j.ejor.2006.08.043

Lili, Z., \& Dongyang, D. (2012). The Bayesian hierarchical credit risk assessment model based on the MCMC simulation. Journal of Statistics and Information BBS, 26(12), $26-31$. http://dx.doi.org/1007-3116(2011)12-0026-06

Liu, T., Chong W., \& Min, W. (2005). The Model of Credit Risk Assessment in Commercial Banks on Support Vector Machine. Predicted, 24(1), 52-55. http://dx.doi.org/1003-5192(2005)01-0052-04

Malekipirbazari, M., \& Aksakalli, V. (2015). Risk Assessment in Social Lending Via Random Forests. Expert Systems with Applications, 42(10), 4621-4631. http://dx.doi.org/10.1016/j.eswa.2015.02.001

Perez, M. (2006). Artificial neural networks and bankruptcy forecasting. A State of the Art. Neural Computing \& Applications, 15(2), 154-163. http://dx.doi.org/10.1007/s00521-005-0022-x

Xiaochuan, W., Feng, S., Lei, Y., \& Yang, L. (2013). The 43 case studies of MATLAB neural network. Beijing, BJ: Beijing Aeronautics and Astronautics Press.

Yijun, Z., \& Chi, X. (2013). The impact of cash flow risk to enterprise value study based on CFaR model. Journal of Human Social Science, 2013(4), 54-158. http://dx.doi.org/1009-5675(2013)04-154-05

\section{Notes}

Note 1. http://dx.doi.org/1003-5192(2005)01-0052-04

Note 2. http://dx.doi.org/1003-5192(2005)01-0052-04

Note 3. Xiaochuan, W., Feng, S., Lei, Y., \& Yang, L. (2013). The 43 case studies of MATLAB neural network. Beijing, BJ: Beijing Aeronautics and Astronautics Press.

\section{Copyrights}

Copyright for this article is retained by the author(s), with first publication rights granted to the journal.

This is an open-access article distributed under the terms and conditions of the Creative Commons Attribution license (http://creativecommons.org/licenses/by/3.0/). 